\title{
Multivariate Optimization of Volatile Compounds Extraction in Chardonnay Wine by Headspace-Solid Phase Micro Extraction and Gas Chromatography Coupled with Tandem Mass Spectrometry
}

\author{
Sabrina de Bona Sartor ${ }^{1,2 *}$, Marla Sganzerla1, José Teixeira Filho³ ${ }^{3}$ Helena Teixeira Godoy ${ }^{*}$ \\ ${ }^{1}$ Food Analysis Laboratory, Department of Food Science, Faculty of Food Engineering, University of Campinas (UNICAMP), Campinas, \\ Brazil \\ ${ }^{2}$ Facvest University (UNIFACVEST), Lages, Brazil \\ ${ }^{3}$ Hydrology Laboratory, Faculty of Agricultural Engeneering, University of Campinas (UNICAMP), Campinas, Brazil \\ Email: ^sabrinabsartor@gmail.com, *helena@fea.unicamp.br
}

How to cite this paper: de Bona Sartor, S., Sganzerla, M., Filho, J.T. and Godoy, H.T. (2016) Multivariate Optimization of Volatile Compounds Extraction in Chardonnay Wine by Headspace-Solid Phase Micro Extraction and Gas Chromatography Coupled with Tandem Mass Spectrometry. American Journal of Analytical Chemistry, 7, 712723.

http://dx.doi.org/10.4236/ajac.2016.710064

Received: August 3, 2016

Accepted: October 21, 2016

Published: October 25, 2016

Copyright $\odot 2016$ by authors and Scientific Research Publishing Inc. This work is licensed under the Creative Commons Attribution International License (CC BY 4.0).

http://creativecommons.org/licenses/by/4.0/

(c) (i) Open Access

\begin{abstract}
A method for optimization of extraction of volatile compounds in Chardonnay wine was developed using headspace-solid phase microextraction (HS-SPME) and gas chromatography coupled with triple quadrupole tandem mass spectrometry (GCMS/MS). Optimization of the HS-SPME conditions, temperature $\left(\mathrm{T},{ }^{\circ} \mathrm{C}\right)$ and extraction time ( $\mathrm{t}$, minutes), was carried out using a $2^{2}$ factorial central composite rotational design (CCRD). Total area of chromatographic peaks of nineteen compounds was monitored in order to identify the best response and the data was collected on multiple reaction monitoring (MRM) mode. The mathematical model that describes the response surface for the CCRD was validated using the analysis of variance (ANO VA) with $95 \%$ of confidence level. This model showed a lack of fit based on mean square pure error ratios for each response, in which $\mathrm{F}_{\text {calculated }}$ was 2.23 higher than $\mathrm{F}_{\text {tabulated }}$. Even though the models cannot be rigorously used to make quantitative predictions, the coefficients of the model, especially the linear ones, are useful for understanding systematic behaviour of the response values as a function of the factor levels. Multivariate statistical design can be used in optimization of HS-SPME extraction parameters with reduced number of experiments and can be useful in sampling method of volatile compounds of Chardonnay wines analysis by CG-MS/MS. The optimal condition achieved in this method was $30^{\circ} \mathrm{C}$ and 45 minutes of extraction.
\end{abstract}




\section{Keywords}

Chardonnay, GC-MS/MS, HS-SPME, Multivariate Optimization, Volatile

Compounds

\section{Introduction}

Volatile compounds directly contribute to wine aroma which is a fundamental characteristic of identity, quality and acceptance by the consumer market. These compounds form a matrix capable of stimulating a response by the sensory human olfactory system [1]. Several hundred volatiles compounds have been previously identified in wine, belonging to different chemical classes such esters, alcohols, ketones, aldehydes, fatty acids, terpenes, $\mathrm{C}_{13}$-norisoprenoids, methoxipyrazines and sulphur compounds [2]. Although several compounds have been reported to contribute to the aroma of wines, only $10 \%$ of them are considered to be important contributors to the final aroma. The composition and intensity of these compounds depend on several factors, such as the grape cultivar used, grape ripeness degree, climate conditions, soil, microorganisms used in fermentation process, winemaking techniques and aging [3]-[6].

Due to the complex chemical composition of wines, matrix where the aroma compounds are present, a efficient method of extraction is needed to isolate the target analytes as well as serving as a tool for pre-concentration increasing sensitivity of the analytical system used. Several extraction methods for the analysis of volatile compounds in wines, techniques of distillation, solvent extraction and solid phase extraction (SPE) have been reported in the literature [7]. Currently, the most used extraction method for the analysis of volatile compounds in grapes and wines is the solid phase microextraction (SPME) [8] [9].

Introduced by Arthur and Pawliszyn in early 1990's [10], SPME is a sorptive sample preparation technique which involves exposure of extraction phase, dispersed on a solid support, under controlled conditions, in direct contact with the sample (IS-SPME) or with the headspace (HS-SPME). The process includes two basic steps: the first, initiating with a partition of the analytes between the sample and the fiber coating material and the second, desorption of analytes concentrated on fiber to an analytical instrument [11]. The main advantages of this technique are short preparation time, small volume of sample required, possibility of concentration of analytes in liquid, gaseous and solid samples, reduced manipulation by analyst and specially is a solvent free techinique [11] [12]. SPME has been used routinely coupled with gas chromatography (GC) and gas chromatography-mass spectrometry (GC-MS) being successfully applied to extract a wide variety of compounds, specially for the extraction of volatile and semi-volatile organic compounds in complex matrices [11] [13].

Considering that SPME technique is an equilibrium technique with the maximum sensitivity obtained in an equilibrium point instead of an exhaustive one, during devel- 
opment of a SPME method some parameters must be optimized. Usually, the parameters monitored are the type of fiber coating, sampling mode (direct immersion or headspace), agitation, time, temperature, ionic strength, $\mathrm{pH}$, volume of sample, type of vial used, volume of headspace, conditions of desorption [4] [9] [11] [13] [14]. In these cases, where many factors can influence the response of the method, the optimization of extraction procedures can be conducted using multivariate statistical analysis allowing simultaneous variation of all factors studied, being useful for locating the interactions between them and the changes do not detectable in traditional univariate analysis. These tools can provide reliable information about the best analysis conditions and existence of experimental errors. One of the most used tools in multivariate statistical analysis is central composite design (CCD) and response surface methodology (RSM) [15] [16].

Traditionally, gas chromatography coupled to mass spectrometry (GC-MS) is the most used technique for the analysis of volatile compounds in wine [7]. In gas chromatography coupled to tandem mass spectrometry (GC-MS/MS) molecules of interest are fragmented twice, isolated as a fragment and generates a specific spectrum obtained from the selected ions. The use of GC-MS/MS provides a high degree of certainty in the identification of the analyte due to its greater selectivity and sensitivity as compared to the GC-MS. As a result, this technique has been widely used in the detection of compounds presents in low concentrations in complex matrices such as pesticide residues in different food [17], anabolic drugs in human urine [18], volatile organic compounds in water [19] and multi-mycotoxin method for food products [20].

The aim of this work is to optimize a extraction method of volatile compounds in Chardonnay wine using solid phase micro extraction in headspace mode (HS-SPME) and analysis by gas chromatography coupled to tandem mass spectrometry (GC-MS/ MS). Temperature and extraction time were optimized using multivariate statistical analysis with a $2^{2}$ factorial central compound rotational design (CCRD) and response surface methodology for determining the optimum condition of extraction.

\section{Material and Methods}

\subsection{Reagents and Standards}

Analytical standards used were 1-hexanol, 3-methyl-1-butanol, 2-phenylethanol, isoamyl acetate, hexyl acetate, ethyl lactate, diethyl succinate, ethyl butanoate, ethyl hexanoate, ethyl octanoate, ethyl decanoate, hexanoic acid, octanoic acid, decanoic acid, nerol, linalool, $\alpha$-terpineol, $\alpha$-ionone and $\beta$-ionone, purchased from SigmaAldrich (Saint Louis, MO, USA), with purity $\geq 99 \%$. A synthetic model wine was prepared with water previously purified in a Milli-Q $Q^{\circ}$ system (Millipore, Bedford, MA, USA), 12\% (v/v) of ethanol HPLC grade (JT Baker, Xalostoc, México) and 2 $\mathrm{g} \cdot \mathrm{L}^{-1}$ of tartaric acid (Merck, Darmstadt, Germany). The $\mathrm{pH}$ was adjusted to $3.2 \mathrm{using}$ sodium hydroxide $(\mathrm{NaOH}) 1 \mathrm{M}$. Sodium chloride $(\mathrm{NaCl})$ was purchased from Vetec (Rio de Janeiro, Brasil). 


\subsection{Sample Preparation and SPME Procedures}

Samples of Chardonnay wine were obtained in local market in Campinas, São Paulo, Brazil, and four bottles of a same production lot were used in experiments. Wines were produced in Andradas, Minas Gerais, Brasil (22 $\left.04^{\prime} 04^{\prime \prime S} 46^{\circ} 34^{\prime} 08^{\prime \prime} \mathrm{W}\right)$ in 2011 vintage. For analysis, $10 \mathrm{~mL}$ aliquots of wine were pipetted into a $40 \mathrm{~mL}$ SPME vial, $3.0 \mathrm{~g}$ of sodium chloride was added and complete with screw-top caps and PTFE/silicon septa (Supelco Inc., Bellefonte, PA, EUA). During the sampling time, sample was constantly stirred with a small magnetic stirring bar. SPME fiber (Supelco Inc., Bellefonte, PA, EUA) used in this study was $50 / 30 \mu \mathrm{m}$ with divinylbenzene/carboxen/ polydimethylsiloxane (DVB/CAR/PDMS) coating conditioned before use according to the manufacturer's instructions. DVB/CAR/PDMS fibers were chosen according to the range of polarity and different functionalities of the mixture of molecules analyzed in this study: alcohols, esters, fatty acids, $\mathrm{C}_{13}$-norisoprenoids and monoterpenes. Fiber was exposed to the sample headspace after equilibrium time of 10 minutes. The factors optimized were time of fiber exposure and temperature of sample, due to their influence in equilibrium system. After extraction, fiber was introduced into gas chromatography injector for desorption of the analytes at a temperature of $270^{\circ} \mathrm{C}$, in splitless mode for 15 minutes.

\subsection{Gas Chromatography Coupled to Tandem Mass Spectrometry (GC-MS/MS)}

The GC-MS analysis were performed on a Agilent 7890A gas chromatograph (Agilent Technologies, Palo Alto, CA, EUA) equipped with a Agilent 7000 Triple Quad mass detector (Agilent Technologies, Palo Alto, CA). Liner used was specific for SPME analysis purchase from Sigma Aldrich (Saint Louis, MO, USA), with $0.75 \mathrm{~mm}$ of internal diameter. Chromatographic separation was achieved using a capillary column Supelcowax 10 (100\% polyethyleneglycol) (Supelco Inc., Bellefonte, PA, EUA.) with following dimensions: $30 \mathrm{~m} \times 0.25 \mathrm{~mm} \times 0.25 \mu \mathrm{m}$. Carrier gas was high purity Helium at a constant flow of $1.0 \mathrm{~mL} \cdot \mathrm{min}^{-1}$ in splitless injection mode. The injector temperature was $270^{\circ} \mathrm{C}$ and oven temperature program initialize with $30^{\circ} \mathrm{C}$, was held for 2 minutes and then increasing $4^{\circ} \mathrm{C} \mathrm{min}^{-1}$ to $130^{\circ} \mathrm{C}\left(2\right.$ minutes) followed to increase $8^{\circ} \mathrm{C} \mathrm{min}^{-1}$ to $250^{\circ} \mathrm{C}$ (5 minutes) [21]. Solvent delay used was 2.5 minutes.

Mass spectras were obtained by using electron impact (EI) as ionization mode and $-70 \mathrm{eV}$ as electron energy. Temperatures of interface, source and quadrupoles (Q1, Q2 and Q3) were $250^{\circ} \mathrm{C}, 260^{\circ} \mathrm{C}$ and $150^{\circ} \mathrm{C}$, respectively. Nitrogenium and Helium were used in collision cell (Q2) at $2.25 \mathrm{~mL} \cdot \mathrm{min}^{-1}$ and $1.5 \mathrm{~mL} \cdot \mathrm{min}^{-1}$ flows, respectively. Acquisition was performed in multiple reaction monitoring (MRM) mode. Precursor ions were used as qualifiers and product ions were as identifiers (Table 1). Mass range analyzed was from 30 to $400 \mathrm{~m} / \mathrm{z}$ and 50 milliseconds of acquisition time. Resolution of MS1 and MS2 was set in wide mode. Collision energy (CID) was chosen to different analytes and are showed in Table 1. Dwell time was set in 1 milliseconds for all analytes. 
Table 1. GC-MS/MS parameters of compounds analyzed in HS-SPME optimization strategy.

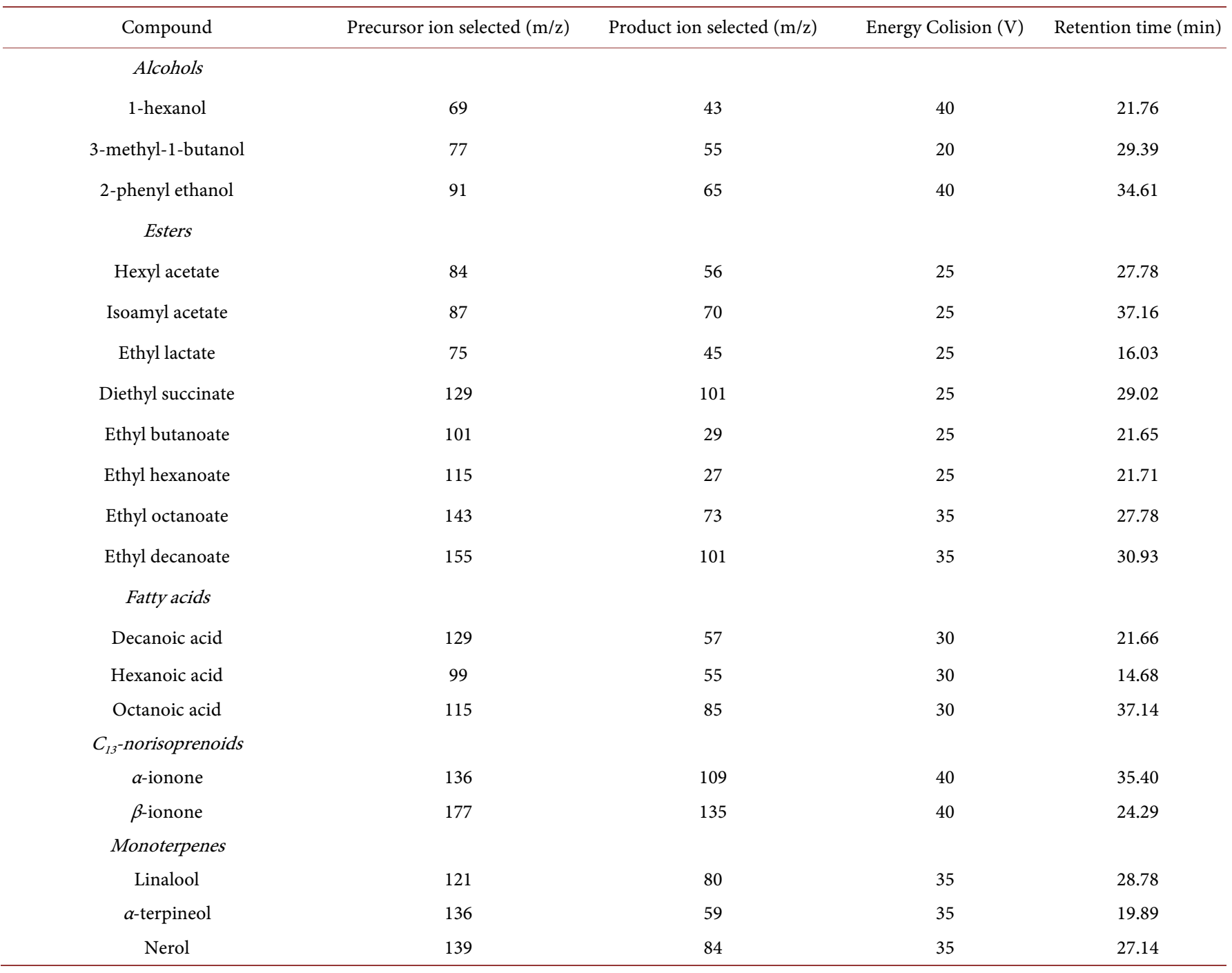

Data were acquired and processes using Agilent Mass Hunter software (version B.05.00, Agilent Technologies). The compounds identification was achieved by comparing the retention time and mass spectra obtained from sample with standards compounds presented in a model synthetic wine injected at same conditions. Qualifier and identifier ions were considered positive when they showed similarity of at least $75 \%$ with the standards prepared and analyzed as well as comparing the MS fragmentation with the mass spectras present in the National Institute of Standards Mass Spectral Library (NIST 2011).

\subsection{Optimization Strategy}

Optimization of the HS-SPME conditions was carried out using a $2^{2}$ factorial central composite rotational design (CCRD) with four axial points $(\alpha=1.4142)$ and tree central points [22]. Variables chosen were the temperature $\left(\mathrm{T},{ }^{\circ} \mathrm{C}\right)$ and extraction time $(\mathrm{t}, \mathrm{mi}-$ 
nutes) and other parameters (amount of $\mathrm{NaCl}$, equilibrium time, velocity of stirring, sample volume) were arbitrarily established by the authors. The levels of each variable can be seen in Table 2. The values of the factors are adjusted to better control of experiments. Twelve experiments were carried out at random. The software Statistica ${ }^{\oplus}$ v.7 (Statsoft Inc., Tulsa, OK, EUA) was used for statistical analysis.

\section{Results and Discussion}

\subsection{SPME Conditions for Extracting Volatile Compounds}

Volatiles compounds monitored in this study were chosen because they represent the major chemical classes of aroma compounds in wines: alcohols, esters, fatty acids, monoterpenes and $\mathrm{C}_{13}$-norisoprenoids [24]. The fiber used, DVB/CAR/PDMS, was performed in accordance with the interest of this work: cover a wide range of polarity, volatility and functionality represented by selected volatile compounds. Several authors have reported that DVB/CAR/PDMS fiber as the most selective and efficient for the detection of volatile compounds in wines [16] [23] [24]. The amount of salt added is intended to increase the ionic strength and promote "salting out" of the volatile compounds from their matrix by increasing the partition coefficient and also, concentration of the analyte in the headspace before extraction [14] [24]. Theoretically, any inorganic salt may be used but most commonly used salts are sodium sulphate $\left(\mathrm{Na}_{2} \mathrm{SO}_{4}\right)$ and sodium chloride $(\mathrm{NaCl})$ due to their high solubility in aqueous medium (wine) [24]. The concentration used is, usually, 30\% of the sample volume [16] [25]. Sample volume used must be established according to the experimental procedures considering the volume of the vial used, headspace volume, size and depth of fiber exposure to the sample headspace.

Table 2. Experimental conditions and values of response (total area) obtained for the CCRD for the HS-SPME optimization.

\begin{tabular}{cccccc}
\hline \multirow{2}{*}{ Experiment } & \multicolumn{3}{c}{ Factors $^{\dagger}$} & \multirow{2}{*}{ Response $^{\ddagger}$} \\
\cline { 2 - 5 } 1 & $\mathrm{~T}\left({ }^{\circ} \mathrm{C}\right)$ & Extraction temperature & $\mathrm{t}(\mathrm{min})$ & Extraction time $^{*}$ & \\
\hline 2 & -1 & 33 & -1 & 35 & $2.50 \mathrm{E}+07$ \\
3 & 1 & 48 & -1 & 35 & $2.44 \mathrm{E}+07$ \\
4 & -1 & 34 & 1 & 55 & $2.49 \mathrm{E}+07$ \\
5 & 1 & 48 & 1 & 55 & $2.43 \mathrm{E}+07$ \\
6 & -1.41 & 30 & 0 & 45 & $2.54 \mathrm{E}+07$ \\
7 & 1.41 & 50 & 0 & 45 & $2.43 \mathrm{E}+07$ \\
8 & 0 & 40 & 1.41 & 59 & $2.50 \mathrm{E}+07$ \\
$9^{\S}$ & 0 & 40 & -1.41 & 30 & $2.49 \mathrm{E}+07$ \\
$10^{\S}$ & 0 & 40 & 0 & 45 & $2.48 \mathrm{E}+07$ \\
$11^{\S}$ & 0 & 40 & 0 & 45 & $2.49 \mathrm{E}+07$ \\
$12^{\S}$ & 0 & 40 & 0 & 45 & $2.49 \mathrm{E}+07$ \\
\hline
\end{tabular}

${ }^{\dagger}$ : with $\alpha=1.4142{ }^{*}$ : expressed in arbitrary units; ${ }^{\varsigma}$ : central point repetition. 


\subsection{Optimization of Extraction of Volatile Compounds}

Figure 1 shows a Pareto diagram where the data obtained in experiments can be observed. Based on the analysis of the effects of the factors involved in the design, with $95 \%$ confidence level, it can be see that only the temperature factor $\left(\mathrm{T},{ }^{\circ} \mathrm{C}\right)$ was significant in the models evaluated.

Table 2 shows results obtained in the experiments conducted by DCCR where the response, total area of the chromatographic peaks of the nineteen compounds selected and monitored, is expressed in arbitrary units. Moreover, the table also presents the levels of the factors time $(\mathrm{t}, \mathrm{min})$ and temperature $\left(\mathrm{T},{ }^{\circ} \mathrm{C}\right)$ used in the execution of the experiments. Experiment number 5, with extraction temperature at $30^{\circ} \mathrm{C}$ and $45 \mathrm{mi}$ nutes of extraction time (fiber exposure) showed greater chromatographic response with area values on $2.54 \mathrm{E}+07$.

Analysis of variance (ANOVA) with $95 \%$ of confidence was used to determine which factors significantly affect the response of the HS-SPME procedure and validate the mathematical model that describes the response surface of DCCR. Table 3 shows the values obtained by ANOVA. Based on the regression results which shows the existence, or not, of lack of fit of the mathematical model predictions can be based on this model [15] [22].

The statistical significance of regression given by the quadratic means of the residues $\left(\mathrm{MQ}_{\mathrm{R}} / \mathrm{MQ}_{\mathrm{r}}\right)$ or $\mathrm{F}_{\text {calculated }}$ was 395.97 . When comparing, at the level of $95 \%$, the values of $\mathrm{F}_{\text {calculated }}$ and $\mathrm{F}_{\text {tabulated }(5 \%, 6 \%, 95 \%)}$ which value is 4.39 can be observed that $\mathrm{F}_{\text {calculated }}>\mathrm{F}_{\text {tabulated }}$ about 90.2 times, indicating that the correlation between variables can be considered adequate to this model.

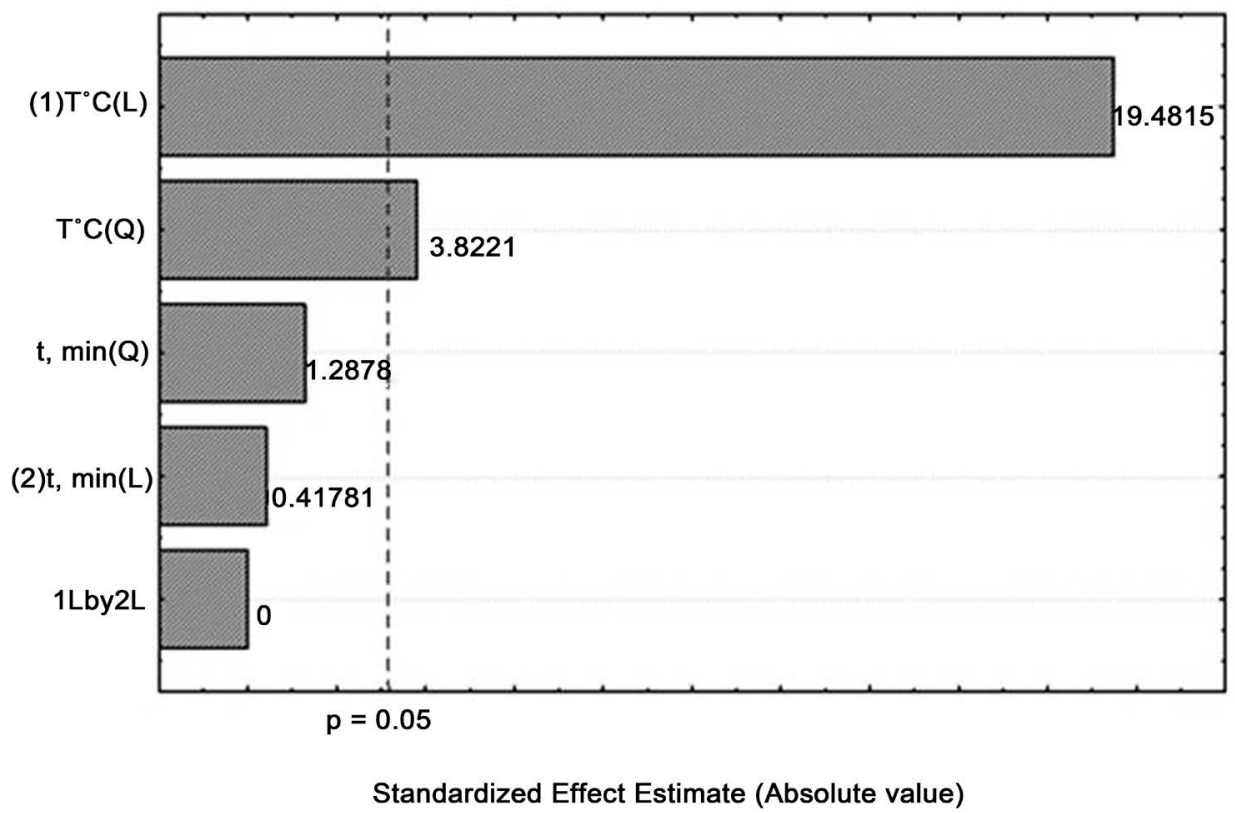

Figure 1. Pareto Chart of standardized effects of $2^{2}$ factorial central composite rotational design (CCRD) for total chromatographic peak area of volatile compounds analyzed by HS-SPME and GC-MS/MS. 
Table 3. Analysis of variance by the minimum squares method for temperature and time of extraction (factors) of volatile compounds in chardonnay wine by HS-SPME.

\begin{tabular}{cccccc}
\hline Sourcesofvariation & Sum ofsquares (SS) & Degreesoffreedom (df) & Mean of the squares (MS) & $\mathrm{F}_{\text {cal }}^{\dagger}$ & $\mathrm{F}_{\text {tab }}^{*}$ \\
\hline Regression & $8.27 \mathrm{E}+11$ & 5 & $1.65 \mathrm{E}+11$ & 395.97 & 4.39 \\
Residues & $1.63 \mathrm{E}+11$ & 6 & $2.71 \mathrm{E}+10$ & & \\
Lack of fit & $1.55 \mathrm{E}+11$ & 3 & $5.17 \mathrm{E}+10$ & 20.68 & 9.28 \\
Pure error & $7.50 \mathrm{E}+09$ & 3 & $2.50 \mathrm{E}+09$ & & \\
Total & $1.14 \mathrm{E}+12$ & 11 & & & \\
$R^{2}$ & 0.720 & & & \\
\hline
\end{tabular}

${ }^{\dagger}: \mathrm{F}_{\text {calculated; }}{ }^{*}: \mathrm{F}_{\text {tabulated. }}$.

Based on the obtained quadratic model was generated response surface to the experiment (Figure 2). Quadratic model generated the equation $\mathrm{R}=2.49 \mathrm{E}+07-3.45 \mathrm{E}+$ $05 \times \mathrm{T}-7.59 \mathrm{E}+04 \times \mathrm{T}^{2}-7.40 \mathrm{E}+03 \times \mathrm{t}-2.56 \mathrm{E}+04 \times \mathrm{t}^{2}$, where $\mathrm{T}$ is the variable 1 (extraction temperature, ${ }^{\circ} \mathrm{C}$ ), $\mathrm{t}$ were variable 2 (extraction time, min) and $\mathrm{R}$ is the response (total area of the chromatographic peaks).

\subsection{Validating the Model Generated for Extraction Conditions}

The process of extraction by HS-SPME involves the partition of the analytes in matrix, in headspace and fiber coating. In the equilibrium, amount of extracted sample is proportional to the partition coefficient and concentration of the analytes in the headspace. Extraction can be considered optimal when the concentration of the analytes reaches equilibrium distribution between the extraction phase (fiber coating) and headspace [8] [9] [12] [26].

In HS-SPME method for extraction of volatile compounds, temperature has great influence on efficiency of the process. The kinetics of the extraction process is directly affected by temperature, as it acts in determining the vapor pressure of the analytes in the matrix [27]. Furthermore, temperature affects directly the partition coefficient of the analyte. The temperature increase, due to thermodynamic conditions, reduces the partition coefficient and hence decreases the amount of analyte extracted [25] [26] [27]. For analysis of volatile compounds in wine, using HS-SPME, temperatures have been reported in literature between $35^{\circ} \mathrm{C}$ and $55^{\circ} \mathrm{C}$. However, these values can be vary depending on the type of wine analyzed, the matrix constituents and concentrations of the analyzed compounds [14] [16] [25].

Extraction time, or fiber exposure to the sample headspace, influences the equilibrium between the phases involved and thus the extraction efficiency. Compounds with a lower partition coefficient, the time required to reach equilibrium must be increased. Compounds with higher partition coefficient require less time to reach equilibrium [12] [25] [28].

The exposure of the fiber for shorter periods of time, or before reach the equilibrium, can make the concentration of the extracted compounds become underestimated. In 


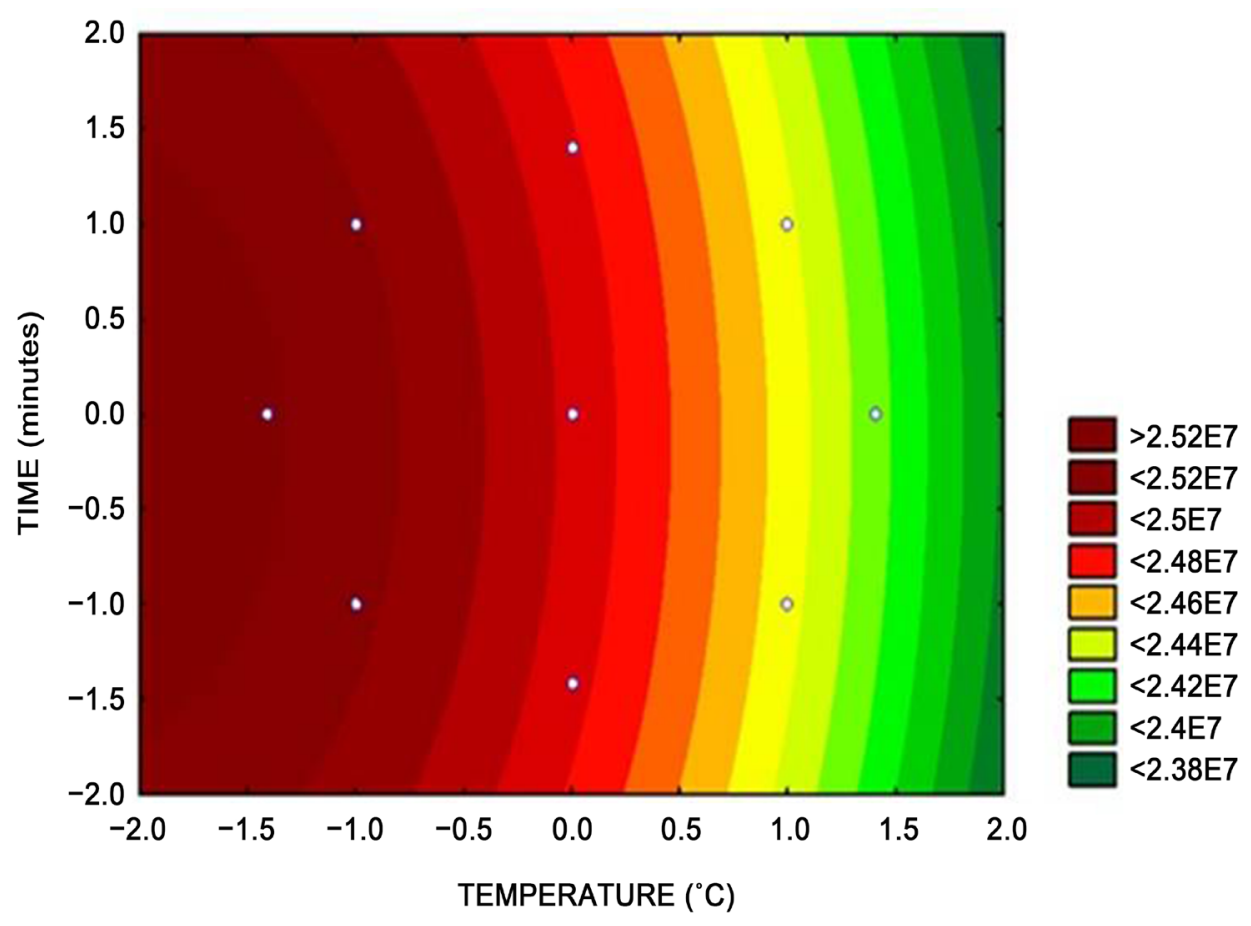

Figure 2. Response surface model (RSM) obtained by central composite rotational design (CCRD) in the optimization of temperature $\left({ }^{\circ} \mathrm{C}\right)$ and time $(\mathrm{min})$ of extraction of volatile compounds in Chardonnay wine using HS-SPME and GC-MS/MS. The equation of RSM, using the quadratic model, is: $\mathrm{R}=2.49 \mathrm{E}+07-3.45 \mathrm{E}+05 \times \mathrm{T}-7.59 \mathrm{E}+04 \times \mathrm{T}^{2}-7.40 \mathrm{E}+03 \times \mathrm{t}-2.56 \mathrm{E}+$ $04 \times \mathrm{t}^{2}$, where $\mathrm{T}$ is the variable 1 (extraction temperature, ${ }^{\circ} \mathrm{C}$ ), $\mathrm{t}$ is variable 2 (extraction time, $\min$ ) and $\mathrm{R}$, the response (total area of the chromatographic peaks).

addition to exposure of the fiber for very long periods of time makes the compounds starts to compete for the active site in the fiber and also affects the final concentration [12] [14] [16] [24]. For the determination of volatile compounds in wines, the extraction time optimized ranged from 30 to 60 minutes [14] [24] [25]. For HS-SPME extraction in wines Chardonnay produced in Rio Grande do Sul, Brazil, and used as a basis for sparkling wine, Welke and co-workers [16] used 45 minutes as the optimum condition of extraction. In this study, the same extraction time (45 minutes) was observed by multivariate analysis, being determined as optimum equilibrium time.

Analyzing the lack of fit of the model generated, based on the values of quadratic mean and pure error of each response where $F_{\text {calculated }}$ was 2.23 times $F_{\text {tabulated }}$. However, for there to be considered a good fit of the model, $\mathrm{F}_{\text {calculated }}<\mathrm{F}_{\text {tabulated }}$ [22] Based on this result, this model could not be used to make predictions about the response. However, considering the optimum extraction point is based in real results, obtained experimentally and with coefficient of variation calculated for the experiments (repetitions) of the central point was considerably low, $0.14 \%$, this model indicate adequate repeatability of the method developed in this condition. Thereby, the coefficients of the model equation even showed lack of fit, can be used for the systematic understanding of response values as a function of factor levels studied [29]. 


\subsection{Gas Chromatography Coupled to Tandem Mass Spectrometry (GC-MS/MS)}

After the HS-SPME extraction process, volatile compound were separated and identified using gas chromatography coupled to tandem mass spectrometry (GC-MS/MS). Confirmation of identity of each analyte was performed comparing the spectra obtained by the injection of analytical standards and between the analytes present in the sample. Use of GC-MS/MS provides a high degree of selectivity, sensitivity and security in identification of compounds [30].

\section{Conclusion}

HS-SPME as extraction method of volatile compounds in wines have been widely used, nevertheless during development of the SPME method, parameters which affects the response must be optimized. In this study, multivariate statistical design was used in optimization of HS-SPME extraction parameters (time and temperature of extraction) with reduced number of experiments. Furthermore, the statistical design provide results to achieve an optimum extraction point of volatile compounds in Chardonnay wine, with temperature in $30^{\circ} \mathrm{C}$ and time of 45 minutes. The combined use of techniques of HS-SPME and GC-MS/MS was suitable for the analysis of volatile compounds in Chardonnay wine.

\section{Acknowledgements}

Authors would like to acknowledge the financial support of Fundação de Amparo à Pesquisa do Estado de São Paulo (FAPESP) (grant number: 2011/17094-2), Conselho Nacional de Desenvolvimento Científico e Tecnológico (CNPq) and Dr. Rodrigo Ramos Catharino (School of Medical Sciences, University of Campinas/UNICAMP) for providing the equipment to carry out chromatographic analysis.

\section{References}

[1] Smyth, H. and Cozzolino, D. (2012) Instrumental Methods (Spectroscopy, Electronic Nose, and Tongue) as Tools to Predict Taste and Aroma in Beverages: Advantages and Limitations. Chemical Reviews, 113, 1429-1440. http://dx.doi.org/10.1021/cr300076c

[2] Ebeler, S.E. and Thorngate, J.H. (2009) Wine Chemistry and Flavor: Looking into the Crystal Glass. Journal of Agricultural and Food Chemistry, 57, 8098-8108. http://dx.doi.org/10.1021/jf9000555

[3] Jiang, B., Xi, Z., Luo, M. and Zhang, Z. (2013) Comparison on Aroma Compounds in Cabernet Sauvignon and Merlot Wines from Four Wine Grape-Growing Regions in China. Food Research International, 51, 482-489. http://dx.doi.org/10.1016/j.foodres.2013.01.001

[4] Medina, K., Boido, E., Fariña, L., Gioia, O., Gomez, M.E., et al. (2013) Increased Flavour Diversity of Chardonnay Wines by Spontaneous Fermentation and Co-Fermentation with Hanseniaspora vineae. Food Chemistry, 141, 2513-2521. http://dx.doi.org/10.1016/j.foodchem.2013.04.056

[5] Añón, A., López, J.F., Hernando, D., Orriols, I., Revilla, E., et al. (2014) Effect of Five Enological Practices and of the General Phenolic Composition on Fermentation-Related Aroma 
Compounds in Mencia Young Red Wines. Food Chemistry, 148, 268-275.

http://www.sciencedirect.com/science/article/pii/S0308814613014921

[6] Liberatore, M.T., Pati, S., Nobile, M.A.D. and Notte, E.L. (2010) Aroma Quality Improvement of Chardonnay White Wine by Fermentation and Ageing in Barrique on Lees. Food Research International, 43, 996-1002. http://dx.doi.org/10.1016/j.foodres.2010.01.007

[7] Polaskova, P., Herszage, J. and Ebeler, S.E. (2008) Wine Flavor: Chemistry in a Glass. Chemical Society Reviews, 37, 2478-2489. http://dx.doi.org/10.1039/b714455p

[8] San-Juan, F., Pet'ka, J., Cacho, J., Ferreira, V. and Escudero, A. (2010) Producing Headspace Extracts for the Gas Chromatography-Olfactometric Evaluation of Wine Aroma. Food Chemistry, 123, 188-195. http://dx.doi.org/10.1016/j.foodchem.2010.03.129

[9] Zhang, M., Pan, Q., Yan, G. and Duan, C. (2011) Using Headspace Solid Phase MicroExtraction for Analysis of Aromatic Compounds during Alcoholic Fermentation of Red wine. Food Chemistry, 125, 743-749. http://dx.doi.org/10.1016/j.foodchem.2010.09.008

[10] Arthur, C.L. and Pawliszyn, J. (1990) Solid Phase Microextraction with Thermal Desorption Using Fused Silica Optical Fibers. Analytical Chemistry, 62, 2145-2148. http://dx.doi.org/10.1021/ac00218a019

[11] Risticevic, S., Niri, V., Vuckovic, D. and Pawliszyn, J. (2009) Recent Developments in Solid-Phase Microextraction. Analytical and Bioanalytical Chemistry, 393, 781-795. http://dx.doi.org/10.1007/s00216-008-2375-3

[12] Zhang, Z., Yang, M.J. and Pawliszyn, J. (1994) Solid-Phase Microextraction. A Solvent-Free Alternative for Sample Preparation. Analytical Chemistry, 66, 844A-853A. http://dx.doi.org/10.1021/ac00089a001

[13] Hayasaka, Y., Baldock, G.A. and Pollnitz, A.P. (2005) Contributions of Mass Spectrometry in the Australian Wine Research Institute to Advances in Knowledge of Grape and Wine Constituents. Australian Journal of Grape and Wine Research, 11, 188-204. http://dx.doi.org/10.1111/j.1755-0238.2005.tb00287.x

[14] Whiton, R.S. and Zoecklein, B.W. (2000) Optimization of Headspace Solid-Phase Microextraction for Analysis of Wine Aroma Compounds. American Journal of Enology and Viticulture, 51, 379-382.

[15] Bogusz Junior, S., de Marchi Tavares de Melo, A., Zini, C.A. and Godoy, H.T. (2011) Optimization of the Extraction Conditions of the Volatile Compounds from Chili Peppers by Headspace Solid Phase Micro-Extraction. Journal of Chromatography A, 1218, 3345-3350. http://dx.doi.org/10.1016/j.chroma.2010.12.060

[16] Welke, J.E., Zanus, M., Lazarotto, M., Schmitt, K.G. and Zini, C.A. (2012) Volatile Characterization by Multivariate Optimization of Headspace-Solid Phase Microextraction and Sensorial Evaluation of Chardonnay Base Wines. Journal of the Brazilian Chemical Society, 23, 678-687. http://dx.doi.org/10.1590/S0103-50532012000400013

[17] Sapozhnikova, Y. and Lehotay, S.J. (2013) Multi-Class, Multi-Residue Analysis of Pesticides, Polychlorinated Biphenyls, Polycyclic Aromatic Hydrocarbons, Polybrominated Diphenyl Ethers and Novel Flame Retardants in Fish Using Fast, Low-Pressure Gas Chromatography-Tandem Mass Spectrometry. Analytica Chimica Acta, 758, 80-92. http://dx.doi.org/10.1016/j.aca.2012.10.034

[18] Delgadillo, M.A., Garrostas, L., Pozo, Ó.J., Ventura, R., Velasco, B., et al. (2012) Sensitive and Robust Method for Anabolic Agents in Human Urine by Gas Chromatography-Triple Quadrupole Mass Spectrometry. Journal of Chromatography B, 897, 85-89. http://dx.doi.org/10.1016/j.jchromb.2012.03.037

[19] Cervera, M.I., Beltran, J., Lopez, F.J. and Hernandez, F. (2011) Determination of Volatile 
Organic Compounds in Water by Headspace Solid-Phase Microextraction Gas Chromatography Coupled to Tandem Mass Spectrometry with Triple Quadrupole Analyzer. Analytica Chimica Acta, 704, 87-97. http://dx.doi.org/10.1016/j.aca.2011.08.012

[20] Rodríguez-Carrasco, Y., Moltó, J.C., Berrada, H. and Mañes, J. (2014) A Survey of Trichothecenes, Zearalenone and Patulin in Milled Grain-Based Products Using GC-MS/MS. Food Chemistry, 146, 212-219. http://dx.doi.org/10.1016/j.foodchem.2013.09.053

[21] Weldegergis, B.T., de Villiers, A. and Crouch, A.M. (2011) Chemometric Investigation of the Volatile Content of Young South African Wines. Food Chemistry, 128, 1100-1109. http://dx.doi.org/10.1016/j.foodchem.2010.09.100

[22] Ferreira, S.L.C., Bruns, R.E., da Silva, E.G.P., dos Santos, W.N.L., Quintella, C.M., et al. (2007) Statistical Designs and Response Surface Techniques for the Optimization of Chromatographic Systems. Journal of Chromatography A, 1158, 2-14. http://dx.doi.org/10.1016/j.chroma.2007.03.051

[23] Castro Mejías, R., Natera Marín, R., de Valme García Moreno, M. and García Barroso, C. (2003) Optimisation of Headspace Solid-Phase Microextraction for the Analysis of Volatile Phenols in Wine. Journal of Chromatography A, 995, 11-20.

http://dx.doi.org/10.1016/S0021-9673(03)00541-7

[24] Howard, K.L., Mike, J.H. and Riesen, R. (2005) Validation of a Solid-Phase Microextraction Method for Headspace Analysis of Wine Aroma Components. American Journal of Enology and Viticulture, 56, 37-45.

[25] Câmara, J.S., Alves, M.A. and Marques, J.C. (2006) Development of Headspace Solid-Phase Microextraction-Gas Chromatography-Mass Spectrometry Methodology for Analysis of Terpenoids in Madeira Wines. Analytica Chimica Acta, 555, 191-200. http://dx.doi.org/10.1016/j.aca.2005.09.001

[26] Zhang, Z. and Pawliszyn, J. (1993) Headspace Solid-Phase Microextraction. Analytical Chemistry, 65, 1843-1852. http://dx.doi.org/10.1021/ac00062a008

[27] Pawliszyn, J. (2000) Theory of Solid-Phase Microextraction. Journal of Chromatographic Science, 38, 270-278. http://dx.doi.org/10.1093/chromsci/38.7.270

[28] Pawliszyn, J. (2009) Handbook of SPME. Chemical Industry Press, Beijing.

[29] Meinhart, A.D., Bizzotto, C.S., Ballus, C.A., Prado, M.A., Bruns, R.E., et al. (2010) Optimisation of a CE Method for Caffeine Analysis in Decaffeinated Coffee. Food Chemistry, 120, 1155-1161. http://dx.doi.org/10.1016/j.foodchem.2009.11.048

[30] Chiaradia, M.C., Collins, C.H. and Jardim, I.C.S.F. (2008) O estado da arte da cromatografia associada à espectrometria de massas acoplada à espectrometria de massas na análise de compostos tóxicos em alimentos. Química Nova, 31, 623-636.

http://dx.doi.org/10.1590/S0100-40422008000300030 
Submit or recommend next manuscript to SCIRP and we will provide best service for you:

Accepting pre-submission inquiries through Email, Facebook, LinkedIn, Twitter, etc. A wide selection of journals (inclusive of 9 subjects, more than 200 journals)

Providing 24-hour high-quality service

User-friendly online submission system

Fair and swift peer-review system

Efficient typesetting and proofreading procedure

Display of the result of downloads and visits, as well as the number of cited articles

Maximum dissemination of your research work

Submit your manuscript at: http://papersubmission.scirp.org/

Or contact ajac@scirp.org 